\title{
Morphological Changes and Enhancement of Ultraviolet Emission by Subsequent Thermal Treatment of Ga-Doped ZnO Nanostructures
}

\author{
U. MANZOOR* \\ Alamoudi Water Chair, King Saud University, P.O. Box 2460, Riyadh, 11451, Saudi Arabia
}

\begin{abstract}
$\mathrm{ZnO}$ nanostructures doped with a high concentration of Gallium (Ga) were synthesized on a Si substrate by thermal evaporation. Subsequent heat treatments of selected nanostructures was done at $600{ }^{\circ} \mathrm{C}, 700{ }^{\circ} \mathrm{C}, 800{ }^{\circ} \mathrm{C}$ and $900^{\circ} \mathrm{C}$. Scanning electron microscope (SEM), X-Ray diffraction (XRD) and photoluminance (PL) studies was performed after every heat treatment. Systematic scanning electron microscope (SEM) studies suggest significant sublimation at $800{ }^{\circ} \mathrm{C}$. XRD results show that crystal quality was improved by annealing and phase separation may occur after high temperatures annealing. Ultraviolet (UV) and visible emission depends strongly on the annealing temperatures and luminescent efficiency of UV emission is enhanced significantly with heat treatment.
\end{abstract}

DOI: $10.12693 /$ APhysPolA.127.910

PACS: $81.05 . \mathrm{Dz}, 78.55$.Et

\section{Introduction}

Recently studies of different doped and undoped $\mathrm{ZnO}$ nanostructures are of great interest in the scientific community owing to their excellent optical, electrical, gas sensing and piezoelectric properties [1-4]. $\mathrm{ZnO}$ nanostructures have inspired scientists. Zno is also one of the most explored materials for practical applications i.e. sensors, transparent conductor oxide (TCO), photocatalysis, etc. [5, 6]. Some of these applications require high electrical conductivity, which may be achieved by replacing $\mathrm{Zn} 2+$ ions with ions of higher valency. For $\mathrm{ZnO}$ nanostructures, group III elements (Al, Ga, or In) are commonly used to substitute $\mathrm{Zn}$ to induce n-type conductivity $[7,8]$. The success of doping is often accompanied and characterized by changes in optical, electrical, and/or structural properties of $\mathrm{ZnO}$ nanostructures. Despite the considerable efforts, rational synthesis of $\mathrm{ZnO}$ nanostructures with tunable n-type conductivity is not available. The as-synthesized $\mathrm{ZnO}$ nanostructures are often randomly oriented, and thus have limited applications in optoelectronic devices.

In gallium-doped zinc oxide (Ga-doped $\mathrm{ZnO}$ ), $\mathrm{Ga}^{3+}$ is expected to cause a small lattice distortion (similar radii sizes of $\mathrm{Zn}$ and $\mathrm{Ga}$ ) and at the same time is an efficient shallow donor in $\mathrm{ZnO}$. However, Ga doping may produce $\mathrm{ZnGa}_{2} \mathrm{O}_{4}$ phase when the doping exceeds a certain limit. Solubility limits are reported to be close to 3 at\% of $\mathrm{Ga}$ in $\mathrm{ZnO}[9,10]$. However, a comprehensive study is required on the effect of annealing on Ga-doped $\mathrm{ZnO}$ nanostructures. This will be important for high temperature applications i.e. gas sensors in which usual operating temperatures are more than $400{ }^{\circ} \mathrm{C}$ [11].

\footnotetext{
* e-mail: umanzoor@ksu.edu.sa
}

In this report, Ga-doped $\mathrm{ZnO}$ nanostructures were heat treated at different temperatures. Temperature dependent degradation in morphology, phase separation and optical properties were studied. Possible reasons for the improvement in optical and structural properties are discussed.

\section{Experimental procedure}

Ga-doped $\mathrm{ZnO}$ nanostructures were synthesized by vapor transport method. Equal amounts (by weight) of $\mathrm{ZnO}$ powder (99.0\%, Hayashi Pure Chemicals Industries, Osaka, Japan) and carbon black were mixed for 4 hours in a ball mill. $0.15 \mathrm{~g} \mathrm{Ga}_{2} \mathrm{O}_{3}$ was added to $0.6 \mathrm{~g}$ of the mixture, mixed using mortar and pasture (source mixture) and loaded into an alumina boat. A Silicon (Si) substrate was placed on top of alumina boat. The boat was then placed at the center of the tube furnace. Ga-doped $\mathrm{ZnO}$ nanostructures were synthesized at $950{ }^{\circ} \mathrm{C}$ with 15 minutes holding time. Argon (Ar) was used as carrier gas and flow rate of $\mathrm{Ar}$ and $\mathrm{O}_{2}$ was 150 and $4 \mathrm{sccm}$ respectively. Morphology was characterized by using scanning electron microscopy (XL30 PHILIPS Netherlands) fitted with Energy Dispersive Spectroscopy (EDX) for elemental analysis. Phase analysis of the deposited nanostructures was done by using $\mathrm{x}$-ray diffraction (XRD Rigaku Tokyo, Japan). Room temperature photoluminescence of the nanostructures was measured using a custom built setup with Xenon lamp and excitation wavelength was $325 \mathrm{~nm}$.

Post-synthesis heat treatment of the Ga-doped $\mathrm{ZnO}$ nanostructures was done at $600{ }^{\circ} \mathrm{C}, 700{ }^{\circ} \mathrm{C}, 800{ }^{\circ} \mathrm{C}$ and $900{ }^{\circ} \mathrm{C}$ for 1 hour in $\mathrm{O}_{2}$ (99.9\% pure) with a flow rate of $25 \mathrm{sccm}$. SEM, XRD and photoluminance (PL) were measured after every heat treatment. 


\section{Results and discussion}

Figure 1a is the typical EDX area scan of Ga-doped $\mathrm{ZnO}$ nanostructures. The results clearly show primary and secondary peaks of Zn and Ga, suggesting that significant amount of $\mathrm{Ga}$ is present. A distinct Si peak is also present which may be here because of the Si substrate. A very small gold $(\mathrm{Au})$ peak is also present, which is from a thin Au coating applied on Si substrate (as catalyst) before the synthesis. Figure $1 \mathrm{~b}$ is the low magnification image of Ga-doped $\mathrm{ZnO}$ nanostructures. The results clearly show mixed morphologies i.e. irregular sheets of different shapes and nanowires. The size, shape and thickness of these sheets are also not consistent and it is difficult to measure the dimensions. These structures are unique in the sense that there are very few reports on mixed morphologies of Ga-doped $\mathrm{ZnO}$ nanostructures [12].

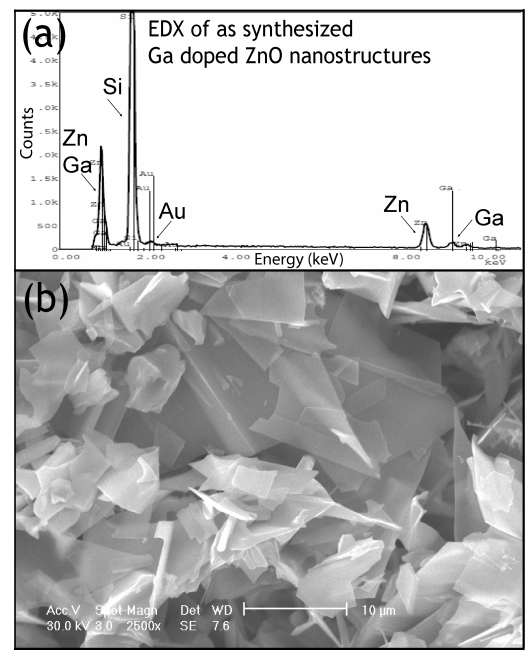

Fig. 1. EDX spectra (area scan) (a) of Ga-doped ZnO nanostructures. (b) SEM image showing mixed morphologies with mostly irregular sheet-shape structures.

Figure 2 shows SEM micrographs of a selected $\mathrm{ZnO}$ sheet shape structure (along with nanowires on top). There is no significant difference in morphology in the as-synthesized sheet and after heating at $600{ }^{\circ} \mathrm{C}$ and $700{ }^{\circ} \mathrm{C}$. SEM micrographs clearly suggest a systematic degradation with temperature after annealing at $800{ }^{\circ} \mathrm{C}$ and $900{ }^{\circ} \mathrm{C}$. Morphological changes are clearly visible at $800{ }^{\circ} \mathrm{C}$. Significant degradation of smaller particles and substructures has started at this temperature, which may be a result of thermal etching. The size of the nanostructures play a significant role and gives a direct evidence that smaller features, having higher surface area are starting to degrade at lower temperatures than the thicker/bigger size particles. A thin film also formed on the substrate and it is expected that the $\mathrm{ZnO}$ sublimated from the nanostructures was deposited. After heating the same substrate at $900{ }^{\circ} \mathrm{C}$, actual nanostructures disappeared and only nanoparticles in the form of a thin film can be seen in the SEM micrograph.

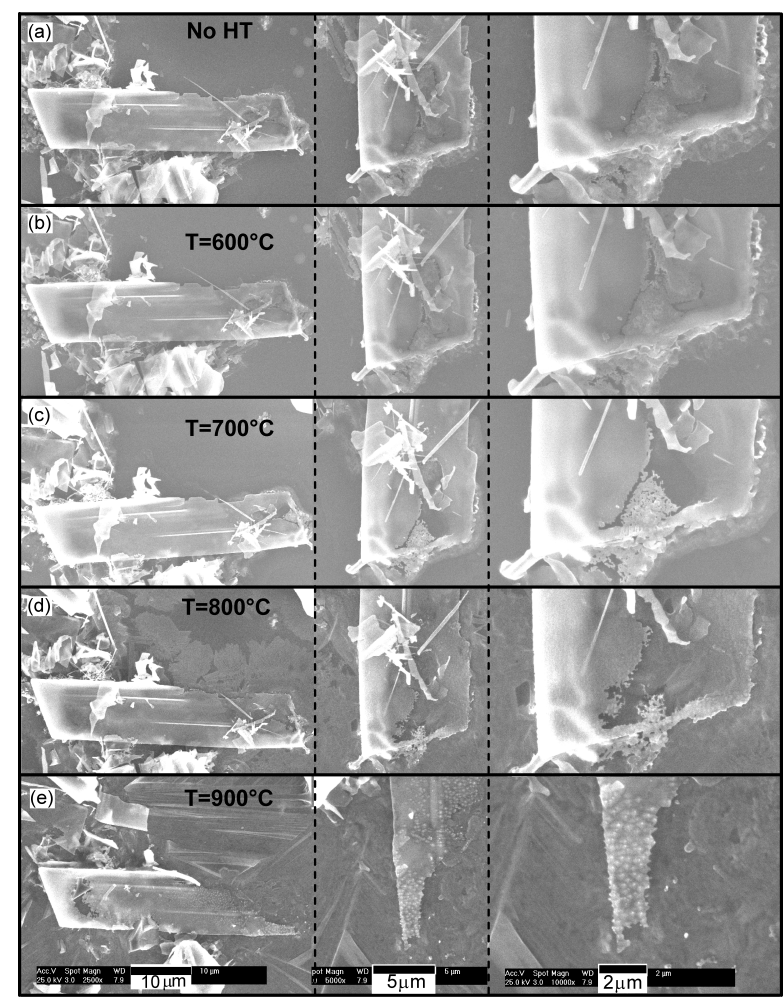

Fig. 2. SEM image (a) of sheet along with nanorods and other irregular structures (b-e) nanocomb, after subsequent heat treatments at $600{ }^{\circ} \mathrm{C}, 700{ }^{\circ} \mathrm{C}, 800{ }^{\circ} \mathrm{C}$ and $900{ }^{\circ} \mathrm{C}$.

Zinc oxide sublimates congruently by decomposition into the gaseous elements according to the following reaction

$$
\mathrm{ZnO}(\mathrm{s})=\mathrm{Zn}(\mathrm{g})+1 / 2 \mathrm{O}_{2}(\mathrm{~g}) .
$$

During high temperature $\left(>700{ }^{\circ} \mathrm{C}\right)$ annealing, the surface morphology of bulk $\mathrm{ZnO}$ is affected by the evaporation of lattice constituents and surface becomes rough due to the continuous evaporation $[13,14]$. As the temperature further increases $\left(900^{\circ} \mathrm{C}\right)$, both $\mathrm{ZnO}$ nanostructures are completely etched out and only nanoparticles are left. Previous reports suggested that prominent sublimation in bulk $\mathrm{ZnO}$ occurs at $1100{ }^{\circ} \mathrm{C}$ [15]. It is interesting to note that sublimation in nanostructures occurred at $800{ }^{\circ} \mathrm{C}$, which is much lower than the synthesis temperature $\left(950{ }^{\circ} \mathrm{C}\right)$. Figure 2 gives direct evidence that $\mathrm{ZnO}$ nanostructures sublimate at much lower temperatures than the synthesis temperature. It may be caused by the nanosize of these structures. Also, the heat treatment was done in pure $\mathrm{O}_{2}$ environment while nanostructures were synthesized in low $\mathrm{O}_{2}$ environment. Therefore $\mathrm{O}_{2}$ environment may also have a significant role in the low temperature sublimation.

XRD results (Fig. 3) clearly suggest change in (i) peak positions and (ii) full width at half-maximum (FWHM) after subsequent heat treatment. XRD results of as synthesized Ga-doped $\mathrm{ZnO}$ nanostructures showed very low 


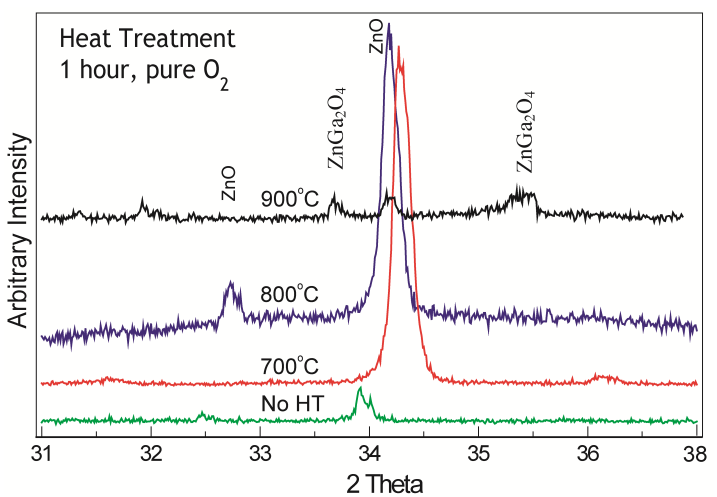

Fig. 3. Comparison of XRD results of Ga-doped $\mathrm{ZnO}$ nanostructures without any heat treatment and after annealing at $700{ }^{\circ} \mathrm{C}, 800{ }^{\circ} \mathrm{C}$ and $900{ }^{\circ} \mathrm{C}$. XRD spectra are direct observation of narrower FWHM after annealing at $700{ }^{\circ} \mathrm{C}$ and $800{ }^{\circ} \mathrm{C}$ and some new peaks appear after annealing at $900{ }^{\circ} \mathrm{C}$.

intensity peaks, suggesting low crystalinity and high defect density. When the same substrate was heated at $700{ }^{\circ} \mathrm{C}$ (after subsequent heat treatment at $600{ }^{\circ} \mathrm{C}$ for 1 hour; XRD data for $600{ }^{\circ} \mathrm{C}$ is not shown) there appeared a peak shift and the narrowing of FWHM. Also, only $\mathrm{ZnO}$ peaks are present, and no peaks of other phases appear in the graph. The shift of the peak and narrowing of the FWHM may be due to high annealing temperatures which enhance the mobility of atoms, subsequently resulting in reduced defect concentration and improve crystal quality [16]. When the same substrate was heated at $800{ }^{\circ} \mathrm{C}$, FWHM is broader as compared to the previous heat treatment and another $\mathrm{ZnO}$ peak appears. This new $\mathrm{ZnO}$ peak may be resulted from the deposited thin film developed on the substrate as a result of sublimation (Fig. 2d). Peak shift towards lower $2 \theta$ can also result from changes in the crystal lattice due to change in defect density and phase separation of Ga atoms. Very interesting and different results are observed after annealing at $900{ }^{\circ} \mathrm{C}$. FWHM of $\mathrm{ZnO}$ peaks again becomes broader, peak intensity becomes very low and new peaks of $\mathrm{ZnGa}_{2} \mathrm{O}_{4}$ phase appear. The angular peak position of bulk crystalline $\mathrm{ZnO}$ with (101) orientation is $2 \theta=34.3^{\circ}$ which is comparable to JCPDS card \#65-3411.

The changes in XRD patterns with subsequent heat treatments reveal some interesting findings. The assynthesized sample initially has low crystalinity. This may be due to Ga doping and/or other crystal defects [17-19]. It is established that deep-level defects in $\mathrm{ZnO}$ can be recovered by annealing the material at high temperatures [20] and this fact is reflected in the XRD pattern of sample annealed at $700{ }^{\circ} \mathrm{C}$. Point defects and other defects are mobile at these temperatures. After annealing the same sample at $800{ }^{\circ} \mathrm{C}$, the high amount of $\mathrm{Ga}$ in the lattice may starts dissolution, which may be the prominent mechanism at this stage, resulting in distortion of crystal and broadening of FWHM. At $900{ }^{\circ} \mathrm{C}$, thermal energy was enough for rejection of excess Ga and phase separation occurred. It is well-known that $\mathrm{ZnGa}_{2} \mathrm{O}_{4}$ is formed when $\mathrm{ZnO}$ and $\mathrm{Ga}$ are mixed together in appropriate conditions [21]. This is reflected in the XRD patterns, the peaks of $\mathrm{ZnGa}_{2} \mathrm{O}_{4}$ are clearly visible in the XRD patterns. In short, XRD patterns suggests that defect density decreases in the initial annealing phase $\left(\right.$ till $\left.700{ }^{\circ} \mathrm{C}\right)$, then again starts to increase $\left(800^{\circ} \mathrm{C}\right)$, further heat treatment $\left(900{ }^{\circ} \mathrm{C}\right)$ results in phase separation. There is also a low intensity peak (below $32.5^{\circ}$ ), for samples not heated and sample heated at $900{ }^{\circ} \mathrm{C}$. These insignificant peaks may appear as a result of small quantities of other/intermediate phases because of high temperature of synthesis and the post heat treatment.

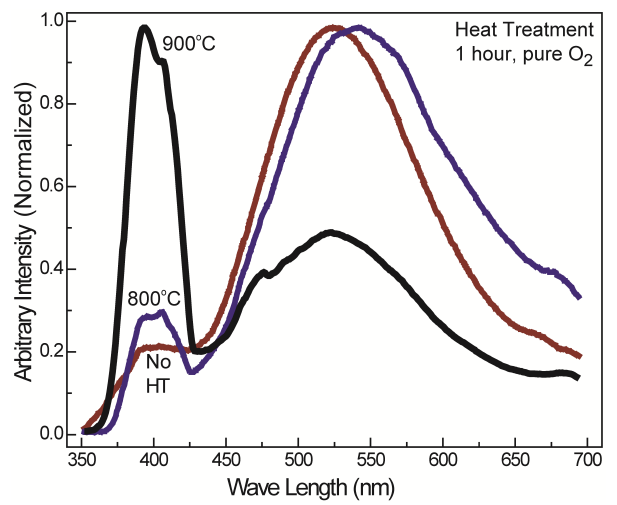

Fig. 4. PL spectra are a clear indication of increase in UV intensity with respect to green intensity after heat treatment at $800{ }^{\circ} \mathrm{C}$. After annealing at $900{ }^{\circ} \mathrm{C}$, NBE peak also splits into 2 peaks at $390 \mathrm{~nm}$ and $410 \mathrm{~nm}$.

Figure 4 is the PL data of Ga-doped $\mathrm{ZnO}$ nanostructures. PL peaks of as-synthesized nanostructures mainly consist of a weak UV emission and a strong green emission. The UV emission, located at $400 \mathrm{~nm}$, is the exciton recombination, related to near-band edge emission (NBE) of $\mathrm{ZnO}$ and the deep-level emission (DLE) at $525 \mathrm{~nm}$ usually results from the radiative recombination of a photo-generated hole with an electron occupying the oxygen vacancy and other defects [22]. Defects are often electrically active and introduce levels in the band gap of the semiconductor, which involve transitions between different charge states of the same defect [23]. Optical properties of $\mathrm{ZnO}$ can be tuned by annealing the samples in different environments [24]. The results suggest that UV intensity (NBE peak) significantly increases after annealing at $700{ }^{\circ} \mathrm{C}$. DLE peak clearly splits into two peaks at $475 \mathrm{~nm}$ and $575 \mathrm{~nm}$. These two peaks are clear indication that defect density and types have drastically changed after annealing at $700{ }^{\circ} \mathrm{C}$, and only specific type of defects are present. Information about atomic diffusion or migration of point defects in $\mathrm{ZnO}$ is currently limited. Activation energies of zinc self-diffusion, in pure $\mathrm{ZnO}$ were reported to be in the range from 1.9 to $3.3 \mathrm{eV}$, while activation energies for oxygen self-diffusion were reported to span a much wider range, from 1.5 to $7.5 \mathrm{eV}[25]$. Doping 
also effects these values and interpreting these results or using them in a predictive manner is not straightforward. After annealing the same sample at $800{ }^{\circ} \mathrm{C}$, there is a blue shift of NBE peak and peak intensities of DLE peaks decrease. Point defects i.e. oxygen vacancy, oxygen interstitial, zinc vacancy, and impurities are considered to be possible cause for these bands [26]. It is well known that DLE related defects cannot be completely removed by annealing and, on the contrary, the annealing conditions actually favor their formation. Point defects at compound semiconductor surfaces are, for entropy reasons, thermodynamically stable at high temperatures [27]. Therefore it is difficult to remove completely the point defects only by thermal treatment in Ga-doped $\mathrm{ZnO}$ nanostructures and a minor peak may always present in the PL data.

When the same sample was annealed at $900{ }^{\circ} \mathrm{C}$, there was again a drastic change in the PL spectra (as in XRD, Fig. 3). NBE peak splits into 2 very distinct peaks at $390 \mathrm{~nm}$ and $410 \mathrm{~nm}$. DLE peaks didn't show significant shift but their relative intensity decreased significantly. The phenomena of NBE peak splitting can be explained by comparing XRD results in which peaks of other phase are clearly visible. It is expected that $\mathrm{ZnGa}_{2} \mathrm{O}_{4}$ is precipitated out as separate phase. The two separate peaks in the UV range can be from the 2 distinct phases appeared after annealing at $900{ }^{\circ} \mathrm{C}$.

XRD results and PL data are in perfect agreement with each other. The increase in UV and XRD intensities suggests decrease in the crystal defects quantity and improvement of the quality of $\mathrm{ZnO}$. XRD peak shift also indicates an improvement in the overall crystal structure. Hence it can be suggested that high annealing temperatures (upto $800{ }^{\circ} \mathrm{C}$ ) provide enough energy to enhance mobility and diffusion/rejection, that could decrease the number of defects and improve overall crystal quality [28]. However, when Ga-doped $\mathrm{ZnO}$ nanostructures were annealed at $900{ }^{\circ} \mathrm{C}$ phase separation occurs and new peaks appear in XRD and PL data.

\section{Acknowledgments}

This project was supported by NSTIP strategic technologies program number (12-WAT-2451-02) in the Kingdom of Saudi Arabia.

This project was also funded by the National Plan for Science, Technology and Innovation (MAARIFAH), King Abdulaziz City for Science and Technology, Kingdom of Saudi Arabia, Award Number (2451).

\section{References}

[1] M. Law, J. Goldberger, P. Yang, Annu. Rev. Mater. Res. 34, 83 (2004).

[2] Kolmakov, M. Moskovits, Annu. Rev. Mater. Res. 34, 151 (2004).
[3] Z. Chen, N. Wu, Z. Shan, M. Zhao, S. Li, C.B. Jiang, M.K. Chyu, S.X. Mao, Scripta Mater. 52, 63 (2005).

[4] Y.S. No, H.Y. Yang, J.Y. Kim, T.W. Kim, J. Ceram. Process. Res. 14, 284 (2013).

[5] Y. Wu, H. Yan, M. Huang, B. Messer, J.H. Song, P. Yang, Chem. Eur. J. 8, 1260 (2002).

[6] L. Zhi-Min, Z. Hong-Zhou, X. Jun, Y. Da-Peng, Chin. Phys. Lett. 22, 987 (2005).

[7] Z.W. Pan, S.M. Mahurin, S. Dai, D.H. Lowndes, Nano Lett. 5, 723 (2005).

[8] S.-H. Yu, J. Yang, Y.-T. Qian, M. Yoshimura, Chem. Phys. Lett. 361, 362 (2002).

[9] Y.H. Leung, A.B. Djurisic, J. Gao, M.H. Xie, Z.F. Wei, S.J. Xu, W.K. Chan, Chem. Phys. Lett. 394, 452 (2004).

[10] M. Amin, U. Manzoor, M. Islam, A. Bhatti, N. Shah, Sensors 12, 13842 (2012).

[11] L.L. Liew, H.Q. Le, G.K.L. Goh, Mater. Res. Innov. 15, 357 (2011).

[12] J.-H. Park, Y.-J. Choi, J.-G. Park, J. Cryst. Growth 280, 161 (2005).

[13] U. Manzoor, D.K. Kim, Physica E 41, 500 (2009).

[14] Z.L. Wang, X.Y. Kong, J.M. Zuo, Phys. Rev. Lett. 91, 185502 (2003).

[15] C. Ma, D. Moore, J. Li, Z.L. Wang, Adv. Mater. 15 , 228 (2003).

[16] A.B. Djurisic, X. Chen, Y.H. Leung, A.M. Ching Ng, J. Mat. Chem. 22, 6526 (2012).

[17] Z.L. Wang, J. Phys: Condens. Matter. 16, R829 (2004).

[18] U. Manzoor, D.K. Kim, Scripta Mater. 54, 807 (2006).

[19] D. Kohl, M. Henzler, G. Heiland, Surf. Sci. 41, 403 (1974).

[20] M. Grunze, W. Hirschwald, D. Hofmann, J. Cryst. Growth 52, 241 (1981).

[21] H. Iwanaga, T Yoshiie, T. Yamaguchi, N. Shibata, J. Cryst. Growth 47, 703 (1979).

[22] K. Vanheusden, W.L. Warren, C.H. Seager, D.R. Tallant, J.A. Voigt, B.E. Gnade, J. Appl. Phys. 79, 7983 (1996).

[23] D.C. Reynolds, D.C. Look, B. Jogai, J. Appl. Phys. 89, 6189 (2001).

[24] W. Gopel, J. Vac. Sci. Technol. 16, 1229 (1979).

[25] J. Lim, K. Shin, H.W. Kim, C. Lee, Mater. Sci. Eng. B 107, 301 (2004).

[26] B. Lin, Z. Fu, Y. Jia, Appl. Phys. Lett. 79, 943 (2001).

[27] H.-J. Ko, T. Yao, Y. Chen, S.-K. Hong, J. Appl. Phys. 92, 4354 (2002).

[28] Y. Zhang, G. Du, X. Yang, B. Zhao, Y. Ma, T. Yang, H.C. Ong, D. Liu, S. Yang, Semicond. Sci. Techn. 19, 755 (2004). 